\title{
Erratum to: Elastic dynamic analysis of synchronous belt drive system using absolute nodal coordinate formulation
}

\author{
Shuai Shuai Jia • Yi Min Song
}

Published online: 27 May 2015

(C) Springer Science+Business Media Dordrecht 2015

\section{Erratum to: Nonlinear Dyn}

\section{DOI 10.1007/s11071-015-2076-3}

The nodal coordinates vector $\mathbf{e}^{j} \mathbf{e}^{j \mathrm{~T}}$ was missing in Eq. (18) in the original publication. Equation (18) is shown correctly below:

$\mathbf{C}^{j}=\frac{1}{2} A \int\left(2 E \gamma_{s}+\frac{8 G \gamma_{d}}{3}\right)\left(\mathbf{S}^{\prime \mathrm{T}} \mathbf{S}^{\prime} \mathbf{e}^{j} \mathbf{e}^{j \mathrm{~T}} \mathbf{S}^{\prime \mathrm{T}} \mathbf{S}^{\prime}\right) d x$

The online version of the original article can be found under doi:10.1007/s11071-015-2076-3.

S. S. Jia · Y. M. Song ( $ه)$

Key Laboratory of Mechanism Theory and Equipment Design of Ministry of Education, Tianjin University, 92 Weijin Road, Nankai District, Tianjin 300072,

People's Republic of China

e-mail:ymsong@tju.edu.cn

S. S. Jia

e-mail:amoschia@126.com 